\title{
Um Projeto de Investigação usando o Laptop UCA na Escola: o andar do Tuiuiú
}

\author{
Maria Helena Nogueira de Sá ${ }^{1}$, Ann Berger Valente ${ }^{1}$ \\ ${ }^{1}$ Pesquisadora bolsista junto ao projeto Abinv, Núcleo de Informática Aplicada à \\ Educação - Universidade Estadual de Campinas (NIED - UNICAMP) - Campinas, SP \\ mhelenasa@gmail.com, annbv126@gmail.com

\begin{abstract}
This paper describes an experience of learning through investigation with second grade students curious about the gait of the enormous bird, Tuiuú. The study was part of the Learning Based on Investigation research project at NIED-UNICAMP. Using research in action methodology, the researchers worked with the classroom teacher to develop the steps in a scientific investigation. The 1:1 educational laptops were used in conjunction with concrete materials and various forms of record keeping. Nevertheless the students were unable to respond to their own question: "Why do the legs of the Tuiuiu bend backwards and not forwards when he walks?"
\end{abstract} \\ Resumo. Esse trabalho relata uma experiência de aprendizagem por \\ investigação com alunos do $2^{\circ}$ ano sobre o andar do Tuiuiú, ave símbolo do \\ Pantanal. $O$ trabalho fazia parte do projeto de pesquisa, Aprendizagem \\ Baseada na Investigação, desenvolvido pelo NIED-UNICAMP. Utilizando a \\ metodologia de pesquisa-ação, as pesquisadoras trabalharam, junto com a \\ professora da classe, para desenvolver os passos de uma investigação \\ científica. Foram utilizados laptops do projeto Um Computador por Aluno, \\ materiais concretos e várias formas de registro. Entretanto, os alunos não \\ conseguiram responder à pergunta definida por eles: "Por que as pernas do \\ Tuiuiú dobram para trás e não para frente quando ele anda?"
}

\section{Introdução}

Esse trabalho relata uma experiência de investigação sobre o grande pássaro pantaneiro, o Tuiuiú, por alunos do segundo ano do Ensino Findamental I que dispunham de acesso 1:1 aos laptops educacionais. O trabalho foi desenvolvido no contexto do projeto de pesquisa "O Laptop Educacional e a Educação Baseada na Investigação: do estudo de fatos científicos para o fazer científico" desenvolvido pelo Núcleo de Informática Aplicada à Educação (NIED) da Universidade Estadual de Campinas. Por sua vez, esse projeto era um desdobramento do Projeto Um Computador por Aluno (UCA) no segmento local do projeto UCA-UNICAMP envolvendo quatro escolas da região de Campinas. Dessa forma, o presente estudo foi realizado na Escola Municipal "Dr. Airton Policarpo" localizada no município de Pedreira $<$ http://escolaairtonpolicarpo.blogspot.com.br/>.

O Projeto UCA, e a proposta que deu origem a ele, da organização One Laptop Per Child (OLPC) tem sido objeto de estudo no Brasil nos últimos anos. Entre $2007 \mathrm{e}$ 2012 encontram-se quase 40 artigos publicados pela Sociedade Brasileira de Computação nos seus veículos voltados para Informática na Educação, entre a Revista Brasileira de Informática na Escola e os anais dos eventos Simpósio Brasileiro de Informática na Educação e Workshop de Informática na Escola. A maioria desses 
trabalhos abordam questões desde a implantação do projeto e formação de professores e gestores escolares, até exemplos práticos de abordagens pedagógicas em sala de aula utilizando os laptops educacionais no processo de ensino e aprendizagem. Os estudos apresentam resultados e questionamentos diversos que, pelo volume da pesquisa, demonstram uma mobilização da comunidade científica em torno das questões técnicas da informática na Educação. Enfim, são evidências do sucesso dessa proposta de inserção maciça da tecnologia no ambiente escolar no sentido de catalisar reflexões e mobilizar mudanças.

A exemplo desse movimento, o projeto de pesquisa "O Laptop Educacional e a Educação Baseada na Investigação", ou como é referido, "Aprendizagem Baseada na Investigação" (ABInv) ${ }^{1}$ teve como objetivo estudar a implantação de uma abordagem pedagógica baseada na investigação, proporcionando assim, situações em que professores e alunos pudessem "fazer ciência" e avançarem na prática cotidiana de somente se estudar os conhecimentos acumulados sobre ciências. Nesse contexto, o laptop educacional permitiu o acesso individual aos meios e ferramentas digitais, junto com outros materiais no ambiente escolar, no processo de vivenciar a experimentação.

Foi proposto à equipe pedagógica da escola Dr. Airton Policarpo, o desenvolvimento de projetos de pesquisa que incentivassem alunos e professoras a fazerem experimentos que os levassem a vivenciar uma aprendizagem por investigação usufruindo-se da situação de um laptop por aluno. A finalidade dessa proposta era avançar na aquisição de habilidades para o uso dos recursos do laptop educacional e propor uma investigação utilizando-se do método científico de pesquisa. Esta abordagem pretendia que, tanto alunos como professoras, passassem pelo mesmo processo de aprendizagem. Procurou-se transformar a aprendizagem em algo divertido, tornando-se bastante acessível os princípios da Ciência e Tecnologia para a tomada de consciência da ciência na nossa vida cotidiana.

A abordagem proposta à escola parecia novidade já que a tecnologia dos laptops UCA, de certa forma, alterara a dinâmica de sala de aula. Porém, esta metodologia não era diferente das normas didáticas oferecidas nos Parâmetros Curriculares Nacionais (PCNs) em que os professores são orientados a criarem projetos de aprendizagem que contemplem a problematização, a experimentação e a sistematização dos conhecimentos. A memorização de informação é substituída por um processo interno de desestabilização de verdades:

"O professor poderá promover a desestabilização dos conhecimentos prévios, criando situações em que se estabeleçam os conflitos necessários para a aprendizagem - aquilo que estava suficientemente explicado não se mostra como tal na nova situação apresentada. Coloca-se, assim, um problema para os alunos, cuja solução passa por coletar novas informações, retomar seu modelo e verificar o limite dele" [Brasil 1997, p. 77]

"É nesse processo intrinsecamente dinâmico de busca de informações e confronto de ideias que o conhecimento científico se constrói." [idem, p.78]

\footnotetext{
${ }^{1}$ ABInv é uma Instância do projeto UCA-UNICAMP-CNPq: "O Laptop Educacional e a Educação Baseada na Investigação: do estudo de fatos científicos para o fazer científico" <www.nied.unicamp.br/abinv>
} 
As orientações proporcionadas nos PCNs vão ao encontro das noções de construcionismo propostas por Papert (1980), um dos pioneiros no uso da tecnologia digital no processo de ensino e aprendizagem. No construcionismo, o enfrentamento com noções conflitantes descrito nos PCNs se dá por meio de construir coisas que são do interesse da criança. Papert propõe que as pessoas externalizem seu pensamento através da manipulação de objetos e, ao construir um artefato (seja um programa no computador, um poema ou um objeto concreto), elas tenham a oportunidade de refletir sobre suas próprias ideias. Ackermann (2004) explica a visão de Papert sobre as transformações mentais que levam à novas aprendizagens:

\begin{abstract}
"Papert se interesse pela dinâmica de mudança. Ele enfatiza a fragilidade do pensamento em períodos de transição. A sua grande contribuição como educador é focar nossa atenção em como as pessoas pensam diante do rompimento de suas convicções, quando pontos de vista alternativos penetram a mente, quando ajustar, esticar e ampliar o ponto de vista do mundo se torna necessário. Papert sempre aponta para essa fragilidade, contextualidade e flexibilidade do conhecimento em construção."[idem, p. 21]
\end{abstract}

Foi seguindo essa linha de pensamento que abordamos o trabalho com a professora e seus alunos do $2^{\circ}$ ano, com idade entre sete e oito anos, na sua investigação do andar do Tuiuiú. O Tuiuiú é uma ave enorme, com asas de quase três metros de extensão, cujo corpo é apoiado por duas pernas extremamente finas as quais, aparentemente, se dobram para trás. É uma estrutura muito contraintuitiva, e foi ela que captou o interesse dos alunos. O presente trabalho descreve o processo de proporcionar experiências e recursos para que a professora e alunos pudessem responder as suas perguntas, desconstruir suas certezas e construir novos conhecimentos.

\title{
2. Metodologia
}

A metodologia adotada nesse estudo foi a pesquisa-ação como definido por Thiollet (2004). A deliberação aqui apresentada se baseou em ações concretas de introduzir novas atividades e materiais no ambiente escolar e escutar os dizeres da professora e dos alunos enquanto atores nessas atividades. A partir dos argumentos e explicações dos atores nosso objetivo, como participantes desse trabalho, era proporcionar o ambiente, as experiências e os recursos para que a professora e alunos pudessem formular e responder suas perguntas. Propusemos-nos a ajudar na condução do projeto viabilizando assim, a investigação dos alunos, utilizando-se de vários recursos, inclusive os laptops UCA.

O trabalho se desenvolveu durante o ano letivo de 2012 na Escola Municipal "Dr. Airton Policarpo," que oferece ensino integral para os alunos do Ensino Fundamental I, de $1^{\circ}$ a $5^{\circ}$ anos. Desde o ano 2010, a escola participou do Curso de Atualização e Formação Continuada e em Serviço de Professor para o Projeto UCA. A formação pela qual passou a equipe pedagógica durante esse período teve como objetivo promover o uso das TICs, em especial das tecnologias móveis - laptops educacionais, em atividades integradas ao currículo escolar. Dessa forma, ao iniciar o ABInv, a equipe já tinha superado os problemas logísticos de implantação do projeto e os professores e gestores já estavam familiarizados com essa tecnologia. A vivência do ABInv permitiu uma nova reflexão sobre o processo de ensino voltado para a 
investigação em que os laptops UCA eram mais um recurso presente no ambiente escolar.

\section{Relato e Discussão}

O presente trabalho começa com uma breve descrição dos princípios de investigação científica abordados com os professores da escola no início do projeto ABInv. Esses princípios nortearam as atividades e foram revisitadas várias vezes ao longo do projeto. Em seguida, relatamos o percurso de uma investigação, a do Tuiuiú, conduzida pela classe do $2^{\circ}$ ano.

\subsection{Esquema de uma investigação}

A formação dada aos professores, proposta no projeto ABInv, orientou-os a seguir algumas etapas para que o experimento se aproximasse o máximo possível da metodologia de pesquisa científica. A principal delas era partir de uma pergunta que fosse de interesse dos alunos e cuja temática constasse do currículo da série. Esse ponto de partida era essencial para garantir a relevância do experimento nas aulas que o professor já desenvolvia e o interesse dos alunos na questão abordada. Buscávamos um projeto que tivesse objetivos bem definidos, que permitisse a elaboração de hipóteses, buscasse fontes de pesquisa e embasamento teórico confiáveis e que proporcionasse a realização de ações práticas para que chegassem à conclusões sobre as hipóteses levantadas. A documentação e socialização dos resultados da investigação completariam o caminho a ser percorrido. A orientação para a professora baseou-se nas etapas de um percurso desejável para condução do experimento com seus alunos: elaborar perguntas a partir de uma observação, desenvolver hipóteses que possam explicar a observação, criar um experimento para testar as hipóteses, definir o cenário da investigação (plano, materiais), coletar dados (registro, acompanhamento), analisar e interpretar os resultados, registrar as conclusões.

\subsection{Levantamento da pergunta}

A primeira etapa do trabalho buscou sondar com os alunos o que gostariam de estudar sobre o tema Animais do Pantanal, conteúdo programático do currículo de Ciências Naturais do livro adotado pela escola "Ler e Escrever". A professora sugeriu que os alunos se ativessem às aves que habitam o pantanal, que não são poucas. Julgava que as crianças, mesmo morando em centros urbanos, tinham contato visual com algumas aves, o que levaria a crer que já possuíam um conhecimento prévio sobre esses animais. Além disso, as aves têm características interessantes como: penas - tipos e cores diferentes de acordo com o habitat; bicos - tipos diferentes de acordo com seus hábitos alimentares e curiosidades sobre a reprodução e seus ninhos.

Para nossa surpresa os alunos se interessaram, logo de início, pelo pássaro símbolo do Pantanal - o Tuiuiú. Relegaram o exótico bico do tucano e a penagem das araras em favor da intrigante característica das pernas dessa ave em relação ao volume de seu corpo e seu modo de andar. As primeiras perguntas que surgiram pelos quatro cantos da sala queriam saber por que aquelas pernas tão longas e finas não quebravam ao suportarem seu peso e como ele conseguia se sentar. E, sobretudo, por que as pernas dobravam para trás e não para frente quando ele andava. 


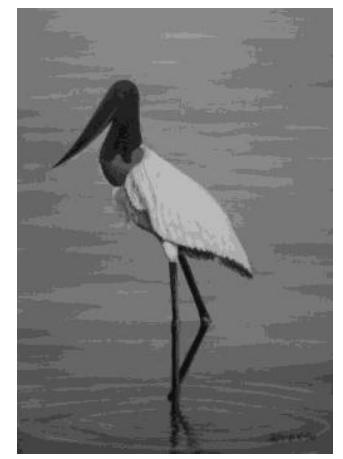

Figura 1. O Tuiuiú

Fonte: Magalhães (2009)

Algumas respostas das crianças lançavam hipóteses interessantes. Achavam que as pernas aguentavam seu peso porque ele ficava muito tempo na água para caçar peixes, como se a água aliviasse o peso do seu corpo; ou porque ele era macio (ou seja, leve, já que tem uma vasta penagem). Para explicarem como o Tuiuiú se sentava, as hipóteses eram mais curiosas ainda. Achavam que ele se dobrava e "quebrava" suas pernas ou, se utilizando de uma metáfora: "As pernas entram dentro dele como as escadas que trocam lâmpada dos postes das ruas".

Mas a pergunta que gerava mais curiosidade por parte das crianças e que parecia não haver resposta era: Por que as pernas do Tuiuiú dobram para trás e não para frente quando ele anda? $O$ experimento passou, então, a buscar a reposta para essa principal pergunta. Seguindo o esquema que orientava as etapas da aprendizagem por investigação, os alunos levantaram algumas hipóteses baseadas nessa discussão das suas observações iniciais:

- Para ajudar a carregar o peso do seu corpo.

- Para que a perna dele não quebre.

- Para ele poder se sentar mais fácil.

- Porque o joelho dele é diferente.

A professora trouxe alguns textos escolares sobre Tuiuiú, mas, infelizmente, não encontraram as respostas que queriam. Assistiram vídeos que mostravam o bonito voo dessa ave tão grande e seu andar intrigante até as águas onde caçava os peixes com seu bico comprido e pontiagudo. Contudo, nós pesquisadoras do processo de investigação, também nos debatemos para entender como funcionava a perna do Tuiuiú. Passamos, a partir daí, a buscar maneiras de ajudá-los na investigação.

\subsection{Adicionar novas informações}

À classe faltavam elementos para dar continuidade na investigação. Era necessária uma intervenção. Na Internet encontramos informações relevantes que poderiam ajudar a turma a encontrar uma solução. Porém, em vez de fornecer uma resposta única, foi criado um blog com links para várias páginas onde os alunos pudessem acessar informações diversas, tirar suas conclusões e registrá-las online na forma de pequenos comentários, cada criança no seu laptop UCA. Especialmente para a turma do $2^{\circ}$ ano, que se encontrava em pleno processo de alfabetização, o multiletramento usando imagem, som e animação favoreceu muito o desenvolvimento da investigação. 
O blog, chamado UCA Tuiuiú, < http://ucatuiuiu.wordpress.com> incluía uma apresentação com vários vídeos sobre o Tuiuiú no seu habitat- o Pantanal, imagens do esqueleto, imagens do interior dos ossos, e as três perguntas principais dos alunos. Um dos vídeos mostrava nitidamente as pernas do Tuiuiú caminhando pelo pântano em busca de comida. As imagens do esqueleto foram diagramas como a seguinte:

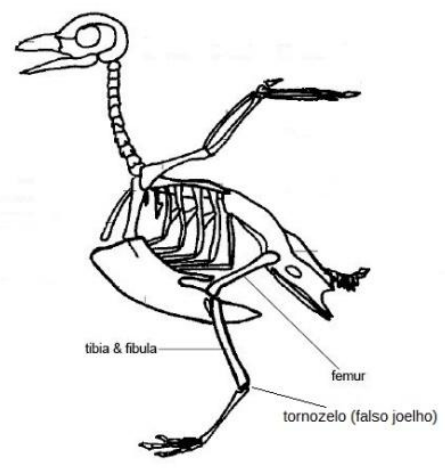

Figura 2. O esqueleto de uma ave grande Fonte: adaptado de Lawson (2013)

$\mathrm{O}$ esqueleto revelou duas diferenças estratégicas entre a anatomia da perna de pessoas e de pássaros. Primeira, a coxa e o joelho do Tuiuiu estão escondidos dentro do corpo. O osso que sobressai para fora do corpo já é a canela (tíbia). Segundo, o osso entre o calcanhar e os dedos é mais fino e comprido do que o do pé das pessoas e se parece com uma canela. Com isso, a articulação que vemos, na realidade, não é o joelho dobrado para trás, mas, sim, o calcanhar que dobra da mesma forma das pessoas.

Mostramos o blog para a professora da sala que desconhecia como era o esqueleto da ave e não tinha pensado nessa explicação. A professora percebeu que o blog trouxe informações novas, sobre os ossos e as propriedades da ave para torná-la mais leve para voar, junto com dinâmicas diferentes usando o laptop UCA. E abraçou a proposta. A classe explorou o blog durante duas aulas e no final da segunda aula nos reunimos para discutir as conclusões enquanto o blog estava projetado no telão.

Foram 19 comentários legíveis registrados no blog baseados nas explorações individuais. Os comentários mostraram que os alunos exploraram bastante as várias informações e tiraram suas próprias conclusões. Os comentários são apresentados na Tabela 2.

Tabela 2. Registro de Observações sobre o Tuiuiú baseado na Internet

\begin{tabular}{|l|l|}
\hline Assunto & Comentário \\
\hline Observações gerais & $\begin{array}{l}\text { ele e maior da gente } \\
\text { o pescoço do tuiuiu é gamde e vermelho }\end{array}$ \\
\hline Sobre o bico & $\begin{array}{l}\text { o bico dele é gamde e forte } \\
\text { o bico dele e afiato }\end{array}$ \\
\hline Natureza dos ossos & $\begin{array}{l}\text { O TUIUIU PODE SEGURA R O SEU CORPO CON SEUS OSSOS } \\
\text { o tuiuiu ele tem os ossos fino } \\
\text { OTUIUIUEMAGROPORDRENTRO ECUAPERNAEMAGRA }\end{array}$ \\
\hline Sobre o esqueleto & A PERNA COMEÇA NO FEMUR. \\
\hline
\end{tabular}




\begin{tabular}{|l|l|}
\hline & $\begin{array}{l}\text { A perna do tuiuiu começa no inicio do rabo } \\
\text { a perna do tuiuiu começa no oso do rabo } \\
\text { O JOELHO FICA ENTRE O FEMUR EPERONE } \\
\text { O JOELHO FICA PERTO DO TIBIU } \\
\text { o tornozelo fica perto do perna } \\
\text { onde esta o joelho [.] estava na perna } \\
\text { o joelho do tuiuiu e virada para trás } \\
\text { por que a perna dele e paratra } \\
\text { dobra joelho para trás } \\
\text { o tuiuiu dobra o juelio para trás }\end{array}$ \\
\hline O movimento & o tuiuiu ele semta \\
\hline
\end{tabular}

Em relação à questão principal da dobra do joelho, notamos que vários alunos confirmaram a hipótese original de que o joelho, sim, dobra para trás. Outros observaram novas relações entre os segmentos da perna. Nas imagens do esqueleto que mostram a ave "por dentro" alguns alunos perceberam que a sequência completa dos ossos da perna estende até a coluna (rabo). Contudo, olhando o Tuiuiú "por fora", vestido com seu corpo e as penas, todos confirmaram que o joelho dobra para trás. Ou seja, as novas informações eram muito abstratas e não desestabilizaram os conhecimentos prévios.

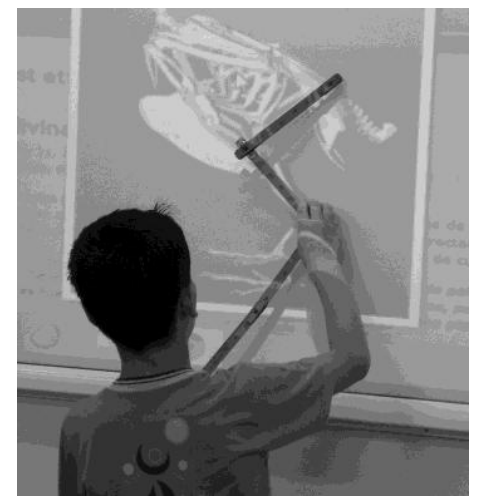

Figura 3. Usando a régua para destacar as articulações da perna

Houve uma tentativa de tornar a imagem do esqueleto um pouco mais concreta usando uma régua de pedreiro como objeto transicional entre a imagem do esqueleto e o próprio corpo das crianças. Mesmo assim, os alunos inventaram justificativas para defender suas hipóteses iniciais, como por exemplo, "Quando ele anda o joelho desce". Os alunos saíram da aula afirmando que o Tuiuiú é uma ave estranha; "Como será que ele dobra a perna para trás?"

\subsection{Recorrer ao concreto}

A professora ficou muito incomodada com essa situação. Percebemos que nossa abordagem foi muito abstrata e que os alunos precisavam explorar material concreto. $\mathrm{O}$ apoio de material concreto para crianças dessa faixa etária, sem sombra de dúvida, seria um apoio fundamental para que construíssem o conhecimento a respeito do assunto.

Por iniciativa própria, a professora resolveu trazer um modelo do Tuiuiú para dar continuidade na pesquisa e encomendou, de um artesão que trabalha com MDF, cinco modelos que os alunos pudessem manipular. A proposta para o experimento seguinte era montar os segmentos das pernas para formar o Tuiuiú. Infelizmente, 
também o artesão não compreendeu as particularidades da perna do Tuiuiú e criou um modelo que representou somente as partes visíveis da perna sem as partes internas do fêmur e joelho, escondidas sob a penagem.
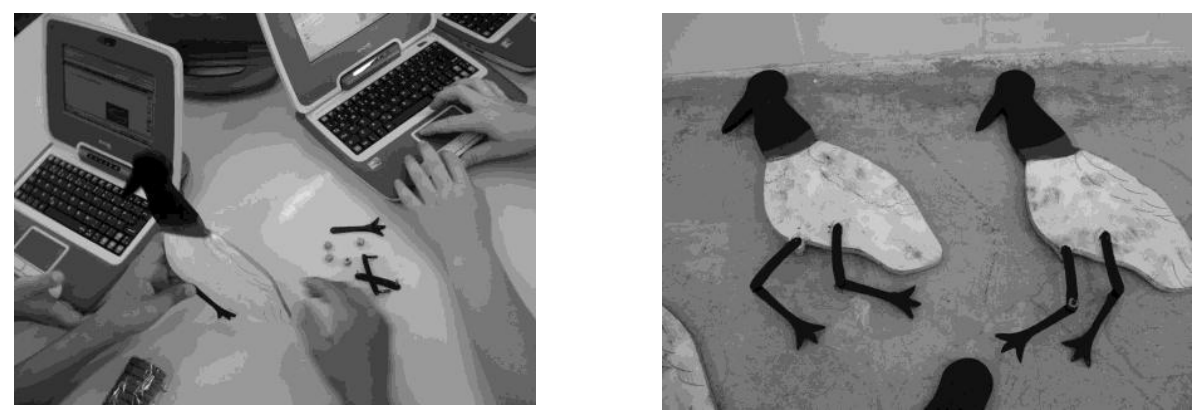

Figura 4. Montando as pernas do Tuiuiú

A expectativa da sala era enorme. Dividimos a classe e cada grupo montou seu Tuiuiú. Entretanto, a atividade veio reforçar as representações iniciais dos alunos, não os levando a reformular suas hipóteses. Inclusive, um dos alunos contou que observou o passarinho da gaiola de sua casa e percebeu que ele também dobrava seu joelho para trás. Esse pequeno cientista fez uso de uma das estratégias da investigação ao procurar em outros contextos evidências relacionadas ao fenômeno para reforçar sua hipótese. Assim, encontrou confirmação da hipótese do joelho invertido ao observar as pernas de outros pássaros que apresentam as mesmas articulações, porém em escala menor.

\subsection{Um Modelo Mecânico}

Percebemos, enquanto pesquisadores, que a desestabilização de certezas entre os alunos dependia de "abrir a caixa preta" da parte interna do Tuiuiú. Era preciso de alguma forma, revelar o movimento do joelho na parte da perna que fica dentro do seu corpo. Relatamos o problema para o NIED e a equipe de robótica ficou sensibilizada com nossa situação. Eles se mobilizaram para criar um modelo mecânico da perna do Tuiuiú.

Apresentamos as imagens do esqueleto e os vídeos do Tuiuiú em movimento para os pesquisadores e, novamente, tivemos que desconstruir a impressão de que o joelho dobra para trás. Percebemos como é muito contraintuitivo. Todos interpretaram as partes do corpo do Tuiuiú baseando-se no próprio esquema corporal onde a articulação no meio da perna é o joelho. "Dava nó na cabeça" projetar as peças e as engrenagens de acordo com o esqueleto do Tuiuiú e não só a parte da perna visível que sobressai de seu corpo.

Faltava uma semana para terminar o ano letivo. O modelo mecânico foi alojado dentro de uma caixa com o desenho de Tuiuiú na frente. No local do corpo abria-se uma porta para espiar o joelho em movimento. Através do laptop UCA as crianças podiam acionar os motores. Levamos o modelo na escola e novamente encontramos a classe na sua usual expectativa. 


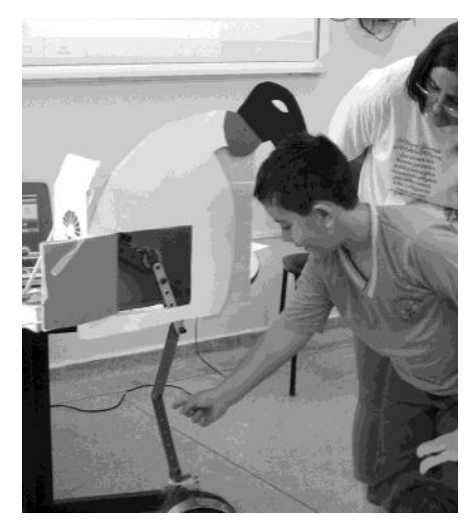

Figura 5. 0 modelo mecânico da perna do Tuiuiú

Infelizmente, apesar da empolgação entre os alunos de colocar a perna em movimento, o nosso modelo não os convenceu. Os alunos se encantaram com as engrenagens e os mecanismos. Terminada a exploração do modelo, foi perguntado novamente se o joelho dobrava pra frente ou para trás e mais uma vez continuaram achando que o joelho dobrava para trás. Alguns alunos tentaram nos agradar respondendo o contrário porque perceberam a nossa frustração, mas no fundo continuavam achando que a perna do Tuiuiu dobra para trás quando ele anda!

Enfim, nós, pesquisadoras, não conseguimos desestabilizar as convicções dos alunos para ajudá-los a encontrar a resposta à sua pergunta. Isso nos levou a refletir novamente sobre suas hipóteses. Uma releitura dessas hipóteses revela, na verdade, que a dobra estranha da perna fazia parte de uma indagação maior sobre a sustentação e o movimento do corpo. Mas se proporcionássemos um protótipo que andasse de fato, a observação desse modelo concreto romperia as convicções? Talvez sim em relação à direção da dobra do joelho. Mas os alunos iriam entender por que a perna tem essa estrutura?

Recorrendo às ideias de Papert sobre construcionismo, talvez se tivéssemos proporcionado um experimento onde os alunos construíssem seu próprio modelo de Tuiuiú, a manipulação dos volumes, pesos e estruturas dos objetos concretos teriam promovido um desequilíbrio nas convicções que até o momento se baseavam somente na observação de modelos prontos. Possivelmente um projeto usando a robótica, em que os alunos pudessem colocar em movimento seus próprios modelos, teria sido mais bem sucedido.

Era preciso mais tempo para explorar como promover esse tipo de experimento com alunos de $2^{\circ}$ ano. Será que crianças da faixa etária de sete e oito anos conseguiriam investigar de forma concreta os conceitos envolvidos no andar do Tuiuiú ou a engenharia envolvida seria muito complexa? São perguntas para uma próxima investigação.

\section{Conclusão}

O trabalho aqui relatado nos revelou diversos aspectos que envolvem um projeto de pesquisa baseado na investigação científica que surgiram em função da demanda dos alunos, professora e das próprias pesquisadoras para elucidar uma pergunta dos alunos. Se por um lado podemos afirmar que todo o processo pelo qual passamos não atingiu o objetivo (aparentemente simples) de um grupo de crianças entre sete e oito anos que era 
o de responder à pergunta "Por que as pernas do Tuiuiú dobram para trás e não para frente quando ele anda?", a riqueza das situações vividas superou a frustração do não entendimento por parte deles sobre as articulaçãoes das pernas do Tuiuiú. Todas as atividades desenvolvidas que incluiram pesquisas guiadas na Internet, compartilhamento de informações, protótipos dessa ave, até a construção de uma engenhoca com recursos da robótica não foram suficientes para desconstruir a imagem que os alunos têm de suas próprias pernas em movimento projetadas nas do Tuiuiu.

Concluímos que as representações que fornecemos não conseguiram chegar ao cerne da questão das crianças. Mas também podemos concluir que, se ficamos frustradas com esse resultado, ele também fica amplamente minimizado se levarmos em consideração todo o processo de construção das etapas de uma aprendizagem por investigação que foi realizado com um grupo de crianças pequenas. A amplitude que ele tomou ao envolver desde o artesão da pequena cidade de Pedreira até os pesquisadores da UNICAMP, é outro aspecto muito relevante. Se a pergunta não pode ser respondida neste momento da vida escolar desse grupo de crianças, esperamos que um dia seja respondida, além de outras tantas, se utlilizando do método científico de investigação. Esse, sim, será o maior legado que essa experiência terá deixado.

\section{Agradecimentos}

Agradecemos ao CNPq pelo apoio ao projeto "O Laptop Educacional e a Educação Baseada na Investigação: do estudo de fatos científicos para o fazer científico" (550382/2011-9)

\section{Referências}

Ackermann, E.K. (2004). Constructing Knowledge and Transforming the World, em: A learning zone of one's own: Sharing representations and flow in collaborative learning environments, M. Tokoro e L.Steels (Eds.). IOS Press, Amsterdam, p. 1537.

Brasil. Secretaria de Educação Fundamental. (1997). "Parâmetros Curriculares Nacionais: Ciências Naturais - Anos Iniciais". Secretaria de Educação Fundamental. - Brasília: MEC/SEF.

Lawson, R. (2007). Anatomy and physiology of animals Birds skeleton. Disponível em <http://commons.wikimedia.org/wiki/File:Anatomy_and_physiology_of_animals_Bi rds skeleton.jpg >, Acesso em ago. 2013.

Magalhães, D. (2009). Tuiuiú. Disponível em 〈http://davincigallery.net/art/t-14191〉, Acesso em ago. 2013.

Papert, S. (1980). "Mindstorms. Children, Computers and Powerful Ideas". New York: Basic Books. Versão em português: Papert, S.M. (1985). Logo: Computadores e Educação. SP, Brasiliense.

Thiollent, M. (2004). “Metodologia da Pesquisa-ação”. São Paulo: Cortez, $13^{a}$ ed. 